\title{
Hemoglobin Tetramer Measurement
}

National Cancer Institute

\section{Source}

National Cancer Institute. Hemoglobin Tetramer Measurement. NCI Thesaurus. Code C135425.

The determination of the amount of hemoglobin tetramer in a biological sample. 